\title{
Diversity Analysis of the Planning of Landscape Construction
}

\author{
Juan Wang
}

Institute of art and design, Huanghe Science and Technology College, Zhengzhou, China, 450063

wjhhkj@163.com

\section{Keywords: Landscape construction, Rational planning, Ecological environment}

Abstract. With the continuous acceleration of our country city changes a course, the environmental problems in the process of modernization in the city is more and more obvious, improve city environment the most effective measure is necessary to the city landscape, provides a good recreation and nature opportunities for the people, for our quality of life and improve the living environment to make the contribution. At present, the landscape project construction scale is expanding constantly, land scape construction on the engineering requirements is also rising, but, in the botanical garden construction process will always appear such problems, to the development of landscape engineering bring certain constraints. How to reasonably plan the development process of garden engineering construction, improve the overall level of landscape engineering, is a modern garden construction personnel urgently needed to solve the problem.

\section{Introduction}

Sustainable landscape ecological construction of city is the precipitation of ecology and sustainable development idea in city landscape. The construction of ecological garden refers to according to the ecology principle to create artificial natural environment, its function mainly includes the general public's life landscape space, improve the aesthetic value of city landscape, dynamic balance adjustment of city ecological system, at the same time also played water flood, purifying the air, protective role against environmental pollution. Compared with the city landscape construction of grey space, with ecological prominent. As a variety of natural ecological elements in the city more concentrated place, landscape construction for the protection of city environment, prevent pollution, regulating the city's ecological balance, regulate temperature, saves the energy, purifying the air, water and soil conservation, reduce city noise, safety protection plays an important role.

\section{The Existence of Landscape Planning and Construction Problems}

Every landscape has its different character of place. The environmental characteristics, the functional requirements of the premises, amount of capital investment and landscape designers my creativity and other factors that determine the landscape ornamental value. For the designers, design should be preceded by a profound understanding of the spirit of place and integrated a variety of factors of creation. Only the designers keep sober consciousness, have deep understanding and into the design of the environment and local culture, construction to perfect to show the artistic design, excellent landscape works will continue to produce.

On the one hand, most of the landscaping project implementation object, are living a life. Through a variety of colored trees, flowers, lawn planting and collocation, make use of the special function of various seedlings, to achieve clean air, vacuum, cooling, sound insulation, building and beautify the living environment; on the other hand, landscaping works also emphasized the pursuit of the beauty of art works, landscaping works in landscape sketch, plant configuration, classical architecture and so on are more artistic, the effect is to give a person with "King" the sense of beauty. And this, in some parts of the design may be difficult to reflect only to achieve the effect, need through the engineering and technical personnel of creative work, the best idea and the realm to achieve design. For example, the rockery, Huangshi revetment, micro terrain handling; in another aspect, the construction personnel skills, planting soil treatment before planting holes, grooves with different skill levels, the momentum out of the artistic effect, it was completely different, the perception of contrast larger. The construction organization design which requires engineering 
supervision and technical personnel for the construction units to submit a detailed review, such as the greening engineering of planting soil treatment before transplanting, seedlings, transportation and planting hole, groove, tree planting, tree transplantation and in civil engineering rockery, plastic mountain, sketch works and landscape lighting engineering in such aspects as to require the construction units is feasible and detailed plan, and pay attention to the overall scheme. The construction scheme adopted in the process of construction must be fully debated, do the construction method of advanced technology, reasonable, safe and civilized construction, is conducive to improve the quality of the project.

Starting from the perspective of landscape planning and design, according to the external morphology, usually the garden will be smaller plants are divided into shrub, Fujimoto, bamboo, flowers, turf six class. Of course, because it is influenced by the climate and other natural conditions, all kinds of plants used in landscape design in different areas are different not only to people's physical and mental pleasure, embody the characteristics, carry forward the thought, considering the health factors, environmental factors in the design of garden plants in the deeper and more science. However, foreign monk good recite scriptures, also good was the phrase used in landscape design. Many developers didn't like landscape design company with indigenous or local, this phenomenon is particularly prominent in Zhengzhou and other inland areas. On the one hand Chinese outstanding landscape design company are mostly concentrated in coastal areas in the south of Shanghai, Guangzhou. Two is the Chinese ingrained "modern" heart was consumed to, think that the moon than China circle. As everyone knows, the most understanding precisely the local climate, environment, plant is the local landscape design company.

At present, the Zhengzhou market south plant disorder introduced, too much emphasis on exotic flowers and rare herbs, often because of abrupt climate change by crowning calamity. Copy offsite and his country greening pattern blindly, often is the ecological and land scape are not guaranteed, for example, in the western suburbs of Zhengzhou a Real Estate Company regardless of o ur climate and soil conditions, in the design of a large number of references in Cinnamomum camphora and Cinnamomum camphora as trees, grown in Zhengzhou can, but the growth of DBH may exceed $15 \mathrm{CM}$. Do not mention the street trees. In addition, due to maintenance and transplant of mismanagement, resulting in a large number of camphor tree growth potential adverse, seedling death phenomenon is serious, heavy losses.

Deal with the problem of soil. As an important issue in the garden construction, the importance of self-evident problems of soil treatment. Plants can grow only in suitable environment is good, and the soil is very important role in plant growth and plays. But in the current landscape construction process, in order to save costs or the requirement of construction period, only the surface soil construction site for processing, while ignoring the soil environment plant root near the plant growth, resulting in not absorb nutrients from soil, destroying the favorable conditions of plant growth.

In addition, its treatment of backfill soil does not pay attention to is also a major problem. On both sides of the road after planting of trees around, just using a simple backfill, no necessary compaction, once encountered during the rainy season, the road will be around appear obvious settlement, has certain influence to the highway roadbed quality in use.

Protection of the original plant. On both sides of the road greening plants in the construction sector, the original plant Road on both sides of the all clear, re grow new plants. This is now in the garden greening is very common, not only cause a waste, but also to the construction inconvenience.

In garden construction, related to the site of the green, is not to say that the original plant all clear, again according to the design department's opinions to greening. But in the design process to the original plant into consideration, design science, reasonable on the basis of the original, so that the original plants used as far as possible on the. One of the original plants are well protected, on the other hand, is also conducive to improve the construction schedule. But no matter how careful transplantation, will cause more or less damage to vegetation, the survival rate can be affected by many factors transplantation. Therefore, in the design of the construction process, if can use the original vegetation, after a simple modification or transformation of design and construction, should 
try to use the original vegetation. At the same time, the original vegetation is also compared with the local natural land scape, can give a person more close to the feeling of nature, reduce conflicts with the local natural landscape greening engineering. To the process of using the original species of design and construction, should pay attention to the protection of the original species, take measures for its enclosure, to prevent human or construction equipment damage to its.

The protection of plant growth environment in the construction of the cross. The construction of garden engineering must cross of construction and civil sector, and this time the most prone to problems. Because regulations and construction principles of different construction units have different interests, they have different influence factors, so it is prone to problems not coordinate between. For example, in the edge of the road stone, masonry to protect these details is the problem occurring place of plant. Construction units to many only consider the convenience for construction, the neglect of the greening of the consideration, in the construction of the plant growth environment caused some damage. In addition, also easy for production process of plant protection frame the problem, once did not follow the design standard, not fully consider the planting a rea, it will cause the design of support frame is unreasonable, cause certain harm to the growth of plants.

\section{The Main Countermeasure in Construction}

Improvement of construction technology. Requirements for the construction of garden engineering technology is still relatively high, including the selection of plants, different plant collocation, seedling cultivation and the growth process of management issues must have a scientific knowledge to guide. This requires the garden construction in the specialized technical personnel to carry out guidance and supervision of the construction process, the technical problems encountered in the construction process, can be solved in time, avoid to cause delays and rework phenomenon in construction, and help to improve the construction quality of garden engineering. At the same time, for the on-site construction personnel of garden engineering, also want to understand some relevant knowledge of garden areas, to avoid adverse consequences caused by blind construction in the construction, we must pay attention to the advanced construction technology study.

Note that the planting position determination, implement fixed-point discharge line processing. Garden greening engineering requirements of planting location accurately, the refore should be designated to put the line determined by planting planting location. In the process of operation, should be strictly in accordance with the design requirements, for obvious mark in the exact location, at the center point of the planting hole marks, planted tank marked edges. In the planting process, should also be carried out in strict accordance with the marker, avoid the influence of greening engineering appearance construction deviation. But in special circumstances should also be flexible, if planning position just happens to have a lamp post or other public facilities, and should maintain a certain distance, usually is suitable for $2 \mathrm{~m}$. Put the line process in the fixed-point, should also take into account the underground pipes, fire hydrants and other factors, timely to make reasonable adjustments to the construction site.

In strict accordance with the growth regularity of planting. To guarantee the survival rate of plants, not only to select the appropriate plant, ensure the soil enviro nmental right, in the process of growing in the earth, should also be consistent with the growth regularity. Before planting and coping with the root crown pruning, ensure the growth of balance, keep part of the underground roots and stems in part on the physiological metabolism balance. In planting should be avoided during the growing season, not suitable for vegetation growth factor reduced in the process of. Such as the need for the project, we must carry out anti season planting, should ensure that multiple factors of soil, air, water and harmonious, choose the suitable weather conditions for planting. Should be avoided in hot or cold weather planting. Summer high temperature structures under the condition of not only to give it a sunshade, from time to time but also regularly to the crown for watering; winter use material wrap trunk insulation would be, to provide optimal growth temperatures. 
The importance of project quality, strengthening personnel management. Landscape engineering project quality directly determines the quality of the whole project benefit and the use of late, good engineering on the development of the landscape industry will also have a certain role in promoting. In the construction, combined with the actual situation, as long as the green area to avoid the neglect of the greening effect, make green style more diversified, enhance the overall effect. In the botanical garden construction process in strict accordance with the construction quality assurance plan for construction, and regular and irregular quality inspection, Reward good and punish the bad, if there is deviation, should take timely corrective actions. In general, the quality of landscape construction project depends on in the construction personnel, construction materials and construction process of three factors, the construction personnel quality consciousness and technical skills is a prerequisite to ensure the construction quality, grasp the construction materials quality is the basis to guarantee the construction quality, Arrange the construction process is the key to ensure the quality of construction.

In construction management, combining training and education, to carry out the necessary professional training for relevant construction participants prior to commencement of construction, in the construction process must have the professional management personnel management and supervision of the construction process for the construction for management oversight and the problems to discover and correct, to ensure that the entire the botanical garden construction projects carried out smoothly and high quality completion.

Strengthen personnel training and theory construction. At present, engaged in landscape engineering professionals are increasingly less liquid, less attention to the cultivation of talent in this aspect most universities, which resulted in the landscape industry practitioners less. Therefore, to establish a training mechanism for a complete garden industry talent personnel training, will rise to a certain height, make people more attention has been paid to the landscape industry. To pay attention to the construction of landscape engineering theory from the view of actual application, the relevant departments, formulate a scientific and rational industry theory, through the theory to the practice and guide the work of landscape engineering.

To pay attention to the construction of landscape engineering theory from the view of actual application, the relevant departments, formulate a scientific and rational industry theory, and the formation of some necessary specification documents, to the landscape construction of certain specification guide. Apply theory to practice, to guide the implementation of land scape engineering.

\section{Conclusion}

Rational planning and landscape construction is a kind of artistic creation, in the construction process should pay full attention to the art of design art idea, will show through the construction. Construction of the garden greening, require the construction units from the preparation to the maintenance a complete system. With the continuous development of garden greening engineering, should continue to take the experience and lessons, promote the construction methods and technology continues to improve, to provide a good living environment and high quality landscape works for the people.

\section{References}

[1] Wang Di. The analysis of space in modern residential area landscape art form of modern decoration [J]. (theory) and 2013 (11).

[2] Sun Junhua. Modern residential landscaping [J]. analys is of private science and technology. $2013(05)$ 